\title{
Weaver-Williams syndrome
}

INSERM

\section{Source}

INSERM. (1999). Orphanet: an online rare disease and orphan drug data base. Weaver-

Williams syndrome. ORPHA:3448

Weaver-Williams syndrome is a multiple congenital anomalies syndrome characterized by moderate-to-severe intellectual disability, decreased muscle mass, microcephaly, facial dysmorphism (prominent ears, midfacial hypoplasia, small mouth and cleft palate), clinodactyly of the fingers, delayed osseous maturation and generalized bone hypoplasia. The syndrome has been described in a brother and sister and an autosomal recessive mode of inheritance has been suggested. There have been no further descriptions in the literature since 1977. 